\title{
Respiratory medicine: bronchiectasis 啮
}

\author{
Authors: Medical Masterclass contributors; edited by John Firth ${ }^{\mathrm{A}}$
}

\section{Aetiology}

Bronchiectasis is a condition that is characterised by the permanent dilatation of bronchi (Figs 1 and 2) from a variety of reasons (Table 1). No definite cause of bronchiectasis is found in over $50 \%$ of patients.

\section{Pathology}

Recurrent bacterial colonisation and infection lead to progressive airway injury that is mediated by neutrophils, T-lymphocytes and monocyte-driven cytokines. Released inflammatory mediators, elastase and collagenase lead in turn to the inflammation and then destruction of the elastic and muscular components of the bronchial walls, resulting in permanent bronchial wall dilatation.

\section{Clinical presentation}

The classic clinical manifestations of bronchiectasis are a cough and daily production of mucopurulent and tenacious sputum: less than $10 \mathrm{~mL} /$ day suggests mild bronchiectasis; more than $150 \mathrm{~mL}$ / day indicates severe bronchiectasis. Other symptoms are listed in Table 2.

Signs of bronchiectasis are shown in Table 3.

\section{Investigations}

Investigations are carried out to confirm clinical suspicion of bronchiectasis, identify any potentially treatable underlying causes, and assess any functional impairment and the extent of the bronchiectasis (Table 4).

\section{Microbiology}

Patients with bronchiectasis usually experience recurrent respiratory tract infections. Prevention of infection and prompt treatment of acute infective exacerbations are cornerstones of management to minimise lung damage and maintain lung function.

Sputum culture should be obtained from patients with bronchiectasis in the stable state and at the time of exacerbation, prior to commencing antibiotics. Pathogens that can be cultured are shown in Table 5.

\footnotetext{
AExtract from Medical Masterclass (third edition, 2018) produced by the Royal College of Physicians and written by over 75 authors and contributors, under the editor-in-chief Dr John Firth
}

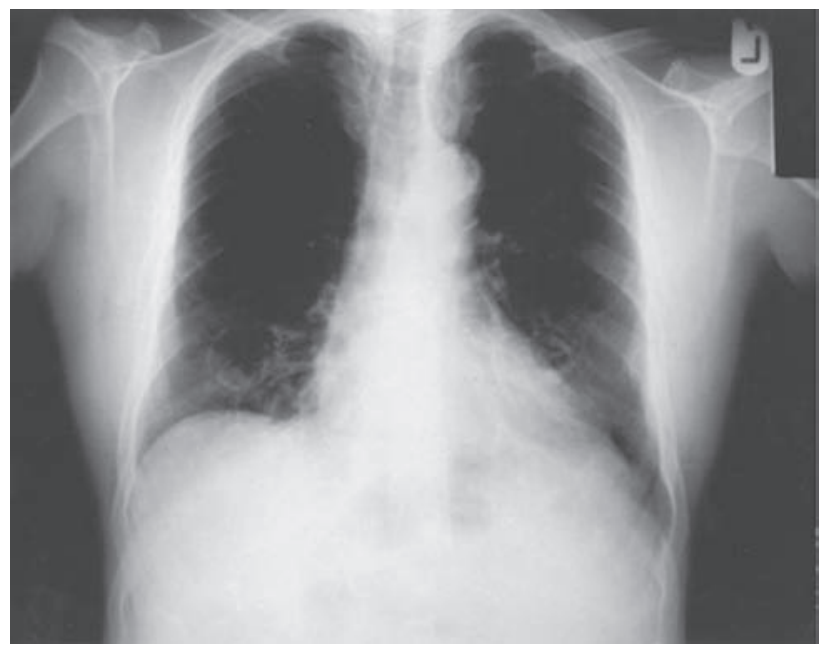

Fig 1. Plain chest radiograph. The tramlines in the right lower lobe are consistent with bronchiectasis.

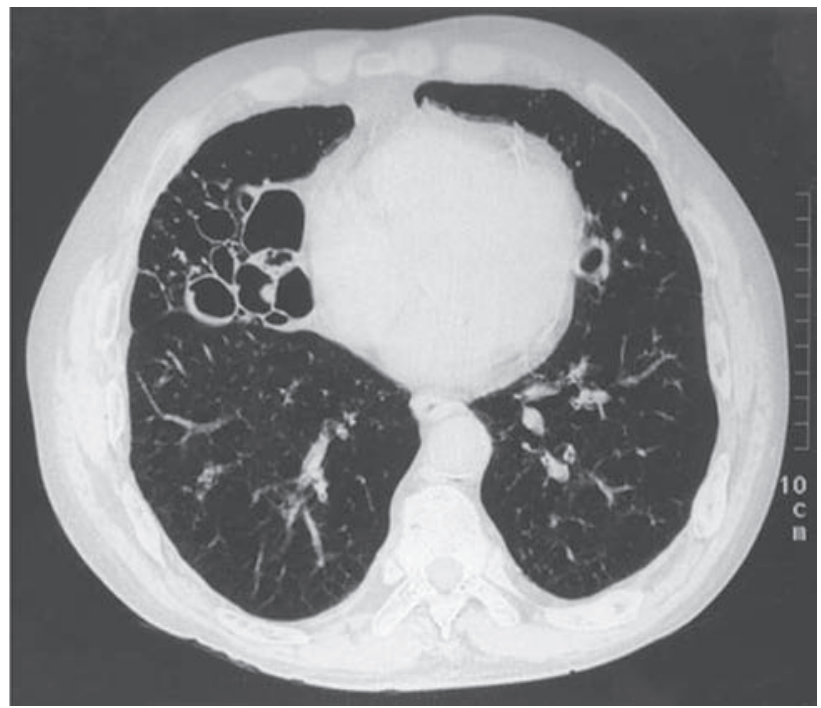

Fig 2. High-resolution CT chest scan. Gross bilateral bronchiectasis, more prominent in the right lung with a classic 'signet ring' appearance generated by an enlarged bronchus and a neighbouring vessel. 
Table 1. Causes of bronchiectasis

\begin{tabular}{|c|c|}
\hline Causes & Examples \\
\hline \multicolumn{2}{|l|}{ Idiopathic } \\
\hline Post-infectious & $\begin{array}{l}\text { Respiratory infection in childhood (measles, } \\
\text { whooping cough or bronchiolitis), pneumonia, } \\
\text { pulmonary TB and non-TB mycobacteria (eg } \\
\text { Mycobacterium avium complex) }\end{array}$ \\
\hline $\begin{array}{l}\text { Bronchial } \\
\text { obstruction }\end{array}$ & $\begin{array}{l}\text { Inhaled foreign body, endobronchial tumour, } \\
\text { extrinsic lymph node / tumour compression } \\
\text { and middle lobe syndrome }\end{array}$ \\
\hline \multirow{2}{*}{$\begin{array}{l}\text { Mucociliary } \\
\text { clearance } \\
\text { defects }\end{array}$} & $\begin{array}{l}\text { Genetic: CF and primary ciliary dyskinesia } \\
\text { (Kartagener's syndrome) }\end{array}$ \\
\hline & $\begin{array}{l}\text { Acquired: Young's syndrome (azoospermia and } \\
\text { sinusitis) and toxic gas inhalation }\end{array}$ \\
\hline $\begin{array}{l}\text { Immune } \\
\text { deficiency }\end{array}$ & Common variable immunodeficiency and HIV \\
\hline Congenital & $\begin{array}{l}\alpha_{1} \text {-Antitrypsin deficiency, Williams-Campbell } \\
\text { syndrome (bronchial cartilage deficiency), } \\
\text { McLeod's syndrome (unilateral emphysema) } \\
\text { and pulmonary sequestration (non-functioning } \\
\text { lung with blood supply from the aorta) }\end{array}$ \\
\hline $\begin{array}{l}\text { Immunological } \\
\text { over-response }\end{array}$ & ABPA and post-lung transplantation \\
\hline Others & $\begin{array}{l}\text { GORD, rheumatoid arthritis, Sjögren's } \\
\text { syndrome, SLE, sarcoidosis, yellow nail } \\
\text { syndrome, ulcerative colitis, Marfan syndrome } \\
\text { and Ehlers-Danlos syndrome }\end{array}$ \\
\hline
\end{tabular}

$\mathrm{ABPA}=$ allergic bronchopulmonary aspergillosis; $\mathrm{CF}=$ cystic fibrosis;

$\mathrm{GORD}$ = gastro-oesophageal reflux disease; $\mathrm{SLE}=$ systemic lupus erythematosus; $\mathrm{TB}=$ tuberculosis

\section{Key point}

Exacerbations of bronchiectasis requiring antibiotics are characterised by:

$>$ increasing sputum volume

$>$ increasing sputum purulence

$>$ increased cough, wheeze or systemic upset.

\begin{tabular}{|c|c|}
\hline \multirow[t]{3}{*}{ Common } & $\begin{array}{l}\text { Crackles (coarse; early inspiratory and late } \\
\text { expiratory) }(70 \%)\end{array}$ \\
\hline & Wheezes $(44 \%)$ \\
\hline & Finger clubbing $(30 \%)$ \\
\hline \multirow[t]{2}{*}{ Uncommon } & Halitosis \\
\hline & $\begin{array}{l}\text { Syndrome specific (eg discoloured nails / } \\
\text { lymphoedema / pleural effusion in yellow } \\
\text { nail syndrome, situs inversus in Kartagener's } \\
\text { syndrome) }\end{array}$ \\
\hline
\end{tabular}

\section{Treatment}

\section{Chest physiotherapy}

This is the cornerstone of treatment, and it is advised that it should be performed at least twice daily. This includes postural drainage, active cycle of breathing techniques, and oscillating positive expiratory devices.

\section{Adjuncts to sputum clearance}

Nebulised saline (normal/hypertonic) assists mucus clearance. Mucolytics (eg carbocisteine) are often used to reduce sputum viscosity, although randomised trial evidence of benefit is limited.

\section{Antibiotics for acute infections}

Send sputum for culture. Start empirical antibiotics, treating for 14 days. Adjust antibiotic therapy directed by sputum culture findings if the patient is not responding. Consider intravenous antibiotics if the patient is very unwell, has not responded to oral antibiotics or has resistant organisms (often Pseudomonas).

\section{Long-term prophylactic antibiotics}

Consider long-term antibiotics if there are more than three exacerbations per year. Send sputum for microscopy, culture and sensitivity (MC\&S) and mycobacterial culture. Select a regimen based on sputum microbiology. Macrolides may have antiinflammatory, disease-modifying effects. Long-term nebulised antibiotics can be considered for patients chronically colonised with Pseudomonas (Colomycin/gentamicin/tobramycin).

\section{Other medical treatments}

Bronchodilators can be given if there is evidence of airflow obstruction. Inhaled corticosteroids are only indicated if there is coexistent asthma.

\section{Interventional techniques}

Bronchoscopy can be used for extraction of mucus (bronchial toilet) if physiotherapy has failed. Bronchial artery embolisation may be used to control severe haemoptysis.

Surgery can be used for symptomatic localised disease (but before doing so it is essential to rule out a systemic disease that may result in bronchiectasis affecting the remaining lung, eg immunodeficiency or aspiration), or massive haemoptysis. 
Table 4. Investigations in bronchiectasis

\begin{tabular}{|c|c|c|}
\hline Test type & Description & Possible findings/indications \\
\hline \multirow[t]{6}{*}{ Generic } & Chest radiograph & $\begin{array}{l}\text { In combination with the clinical presentation this may be sufficient to establish the } \\
\text { diagnosis, although it is not always abnormal. Look for 'tramlines' (parallel thickened lines } \\
\text { representing dilated thickened bronchial walls), ring opacities, band shadows (fluid- or } \\
\text { mucous-filled bronchi), crowded bronchial markings resulting from atelectasis and the } \\
\text { 'finger in glove' appearance that results from impacted central bronchi }\end{array}$ \\
\hline & $\begin{array}{l}\text { High-resolution } \\
\text { CT chest scan } \\
\text { (sensitivity } 97 \% \text { ) }\end{array}$ & $\begin{array}{l}\text { Indicated if there is clinical suspicion of bronchiectasis but a normal chest radiograph, } \\
\text { there are other abnormalities on a chest radiograph that need clarification, or if surgery } \\
\text { may be contemplated. A central (perihilar) distribution suggests ABPA and upper lobe } \\
\text { distribution suggests CF / previous pulmonary TB }\end{array}$ \\
\hline & Lung function tests & Obstructive pattern \\
\hline & Arterial blood gases & Hypoxia and/or hypercapnia in advanced disease \\
\hline & Sputum cultures & $\begin{array}{l}\text { Haemophilus influenzae, Streptococcus pneumoniae, Staphylococcus aureus (if recurrent } \\
\text { this may indicate an atypical presentation of (F) and Pseudomonas aeruginosa }\end{array}$ \\
\hline & Bronchoscopy & $\begin{array}{l}\text { To exclude foreign body / endobronchial lesion or for assessing and localising the source of } \\
\text { haemoptysis }\end{array}$ \\
\hline \multirow[t]{6}{*}{$\begin{array}{l}\text { Specific for } \\
\text { underlying disease }\end{array}$} & $\begin{array}{l}\text { Serum } \\
\text { immunoglobulins }\end{array}$ & IgG / specific IgG (to pneumococcus and $H$ influenzae) / IgA \\
\hline & $\begin{array}{l}\text { Sweat sodium } \\
\text { concentration }\end{array}$ & $\mathrm{CF}$ \\
\hline & CFTR genotyping & CF \\
\hline & $\begin{array}{l}\text { Eosinophils / ABPA } \\
\text { screen }\end{array}$ & ABPA \\
\hline & ACE / calcium & Sarcoidosis \\
\hline & RhF / ANA / ANCA & Rheumatoid arthritis / SLE / vasculitis \\
\hline
\end{tabular}

$\mathrm{ABPA}=$ allergic bronchopulmonary aspergillosis; $\mathrm{ACE}=$ angiotensin-converting enzyme; $\mathrm{ANA}=$ antinuclear antibodies; $\mathrm{ANCA}=$ antineutrophil cytoplasmic antibodies; $\mathrm{CF}=$ cystic fibrosis; CFTR = cystic fibrosis transmembrane conductance regulator; IgA = immunoglobulin A; IgG = immunoglobulin G; RhF = rheumatoid factor; SLE = systemic lupus erythematosus; $\mathrm{TB}=$ tuberculosis

Lung transplantation can be considered for end-stage bilateral disease, usually in patients with cystic fibrosis (CF).

\section{Specific treatments}

> immunoglobulin replacement in common variable immunodeficiency

Table 5. Pathogens cultured from sputum in patients with bronchiectasis

\begin{tabular}{ll} 
Frequency & Organism \\
Common & Streptococcus pneumoniae \\
& Haemophilus influenzae \\
& Moraxella catarrhalis \\
& Staphylococcus aureus (MSSA or MRSA) \\
& Coliforms \\
& Pseudomonas \\
Less common & Non-tuberculous mycobacterium \\
& Mycobacterium tuberculosis \\
& Fungi - Aspergillus \\
\hline
\end{tabular}

MRSA = methicillin-resistant Staphylococcus aureus; MSSA = methicillinsensitive Staphylococcus aureus
> oral steroids and itraconazole in ABPA (there are no data on the efficacy of voriconazole or other imidazole agents in this condition)

> gastric acid suppression and pro-kinetics for recurrent aspiration associated with gastro-oesophageal reflux disease (GORD).

$>$ recombinant human DNase (rhDNase) in CF.

\section{Complications}

> common - recurrent infectious episodes, recurrent pneumonias and cor pulmonale

> uncommon - massive haemoptysis, amyloidosis and brain abscess.

\section{Key point}

Diagnosis

Always pursue the cause of bronchiectasis as finding the cause may lead to treatment that slows or halts the progression of disease.

Treatment

It is essential that the patient's sputum is sent for routine bacterial and mycobacterial microscopy and culture prior to starting antibiotics for exacerbations, although treatment should then not be deferred pending results. 


\section{Prognosis}

Depends on severity, bacterial colonisation (eg Pseudomonas colonisation might be associated with a poorer outcome) and the underlying cause. Deterioration may be due to recurrent and worsening sepsis, or to hypoxia and cor pulmonale.

\section{Prevention}

> vaccination against measles, pertussis, influenza and TB

$>$ prompt treatment of bronchopulmonary infections and ABPA

$>$ early removal of foreign body and obstructing lesions. - 